2016 - Volume: 17 Number: 3

Page: 563 - 571

DOI : $10.18038 / \mathrm{btda} .84126$

Received: 01 April 2016

Revised: 08 August 2016

Accepted: 23 September 2016

\title{
EFFECTS OF WELDING PARAMETERS ON MICROSTRUCTURE AND MECHANICAL PROPERTIES OF FRICTION WELDED AZ91 MG ALLOY
}

\author{
İbrahim ÇELİKYÜREK ${ }^{1, *}$, Emre ÖNAL ${ }^{1}$ \\ ${ }^{1}$ Metallurgical and Materials Engineering Department, Engineering and Architecture Faculty, \\ Eskişehir Osmangazi University, Eskişehir, Turkey
}

\begin{abstract}
The AZ91T5 Mg alloy was bonded by applying continuous drive friction welding machine. The friction load, time and speed were used as friction welding parameters, and the effects of these parameters on the microstructure and mechanical properties of the welding interface were investigated. Characterization of welding interface microstructure and fractured surfaces of joints was carried out by optical microscopy and scanning electron microscopy. Microstructural investigations revealed that the welding interfaces have a smooth and continues morphology. The micro hardness and shear strength of matrix and the welding interfaces were measured in order to determine the mechanical properties of the joints. The results showed that the welding interfaces have higher hardness than the matrix and the shear strengths of welding interfaces increased with increasing pressure and speed while time has different effect.
\end{abstract}

Keywords: AZ91 alloy, Friction welding, Microstructure, Strength, Hardness

\section{INTRODUCTION}

The usage of light weight materials has an important role in the aviation, automotive and transportation industries due to increase of the performance and reduces the energy consumption. Thus, the efforts have been focused on the lighter materials which can provide the same properties. Accordingly, magnesium alloys are interesting materials due to their low densities, high ambient temperature specific strengths, cast ability, thermal stability, and low cost [1]. AZ91 alloys in which the Al is the base alloying element and include some minor other elements resulted the most preferred $\mathrm{Mg}$ alloy. The usage of $\mathrm{Mg}$ alloys have been limited due to some matters such as their low oxidation and corrosion resistance and poor form ability at the ambient temperatures [2].

Joining with welding is the one of the most important and preferred forming technique in the industry. The joining of Mg alloys with themselves and with other materials using fusion and solid-state welding techniques is an important area to increase the usage of these alloys. There are many researches related to the welding ability of Mg alloys, especially for AZ91 alloys, in the literature. The AZ91 alloy can be welded either by fusion welding techniques such as laser welding [3,4], MIG welding [5], TIG welding [6-8], or solid-state welding techniques for example diffusion welding [9], resistance spot welding $[10,11]$, friction stir welding $[2,12]$, and friction stir spot welding $[13,14]$.

On the other hand, some problems which are originated from the nature of $\mathrm{Mg}$ alloys might occur during the fusion welding. The major problems can be their strong affinity to oxygen and nitrogen, low melting and evaporation point, and high thermal conductivity and expansion [7]. The tendency to oxidation burning, porosity, crack formation, large heat affected zone and large weld deformation, and etc. can occur and can deteriorate the performance when compared with the base metal [7]. Most of these problems are avoided by the solid-state welding techniques due to lack of melting and a high quality of the welding process.

Recent works have been focused on friction stir welding, diffusion welding, friction stir spot welding and resistance spot welding for the solid state welding technique. However, the studies related with the

*Corresponding Author: cibrahim@ogu.edu.tr 
friction welding of $\mathrm{Mg}$ alloys are insufficient, while friction welding has been carried out for welding of various metallic materials [15-18]. In this study, AZ91 T5 alloy was welded by friction welding process and results of the effects of welding parameters on the welding interface microstructure and mechanical properties were presented.

\section{METHODS}

AZ91 Mg alloy was fabricated with sand mold casting and T5 heat treatment was carried out. The alloy was machined for the friction welding process on the rod form in diameter of $8 \mathrm{~mm}$. The samples were joined by a continuous drive friction welding machine which is shown schematically in Fig. 1.

The friction welding processes were carried out at friction speeds of 600 and $1000 \mathrm{rpm}$, under 50 and $75 \mathrm{MPa}$ friction pressures with durations of 5,10 , and $15 \mathrm{~s}$. After completing the welding proces, a $150 \mathrm{MPa}$ forging pressure was immediately loaded axially in duration of $10 \mathrm{~s}$. The shortenings in lengths (burn off) were measured by the difference between lengths of the samples pre and post-welding. The microstructures of the welding interfaces were investigated on the perpendicular cross-section of the welds. The micro harnesses of welding interfaces were measured from the center of the welding interface up to the matrix. The strengths of the welding interfaces were determined by a shear test apparatus which is shown in Fig. 2. A part of the welding sample is moveable while the other part is in stationary place which are fixed in the apparatus. After applying a compressive force to the moving part of the apparatus the sample was broken at the welding interface. Shear strength was found by dividing the maximum load to the cross sectional area. After shear tests, the fractured surfaces of the welds were investigated using scanning electron microscopy. The results obtained were evaluated in terms of microstructure, strength and hardness.

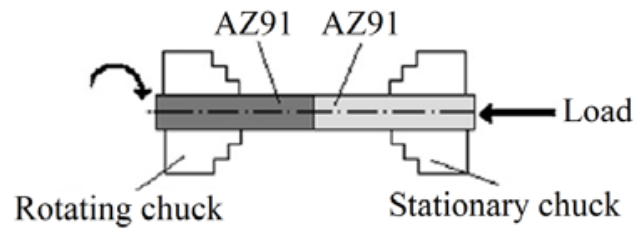

Figure 1. The schematic view of the continuous drive friction welding process [15]

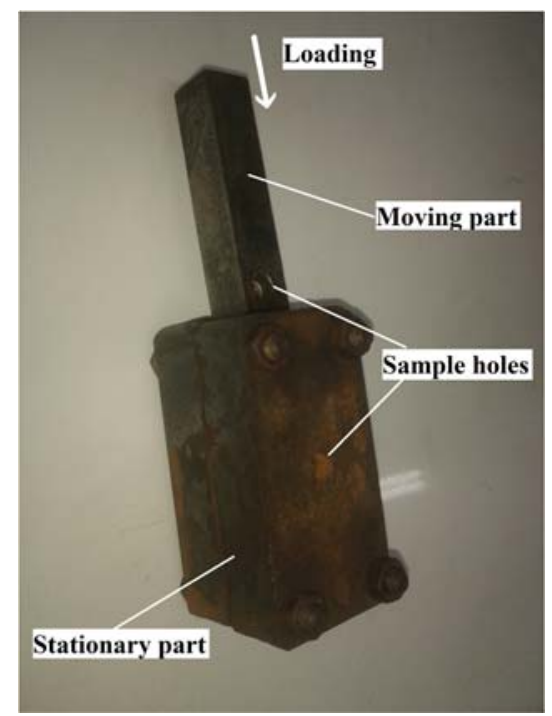

Figure 2. The view of the shear test apparatus [15] 


\section{RESULTS AND DISCUSSIONS}

The friction welding parameters and the burn off values are given in Table 1. As seen from the table, the bonding occurred in most of the welding conditions. Welding was not successful both at the slower speed and in the shorter durations. On the other hand, the burn off value at $1000 \mathrm{rpm}$ speed, under $75 \mathrm{MPa}$ pressure with the duration of $15 \mathrm{~s}$. was looking too much. Thus, the welding was also unsuccessful for these conditions. In these conditions, almost the whole of the samples were wasted via flash formation. The interface temperature increases with increasing friction speed, pressure and time. Due to the pressure applied being higher than the plastic deformation resistance of AZ91 at this temperature, the burn off value increased with increasing speed, pressure and time.

Table 1. The test conditions and burn off values of friction welded samples, $\mathrm{mm}$.

\begin{tabular}{|c|c|c|c|c|c|c|}
\hline \multirow{2}{*}{$\begin{array}{c}\text { Friction } \\
\text { pressure } \\
(\mathrm{MPa})\end{array}$} & \multicolumn{6}{|c|}{ Friction speed (rpm) } \\
\cline { 2 - 7 } & \multicolumn{6}{|c|}{ Friction time (s) } \\
\cline { 2 - 7 } & $\mathbf{5}$ & $\mathbf{1 0}$ & $\mathbf{1 5}$ & $\mathbf{5}$ & $\mathbf{1 0}$ & $\mathbf{1 5}$ \\
\hline $\mathbf{5 0}$ & $\mathrm{X}$ & 2.3 & 5.2 & 3.5 & 4.1 & 9 \\
\hline $\mathbf{7 5}$ & $\mathrm{X}$ & 11 & 30 & 17.6 & 18 & $\mathrm{X}$ \\
\hline
\end{tabular}

The optical microstructures of the all welded samples which show the effect of welding parameters on the welding interface are shown in Fig 3. The welding interfaces have a smooth and continuous morphology for all welding conditions and there is no crack or pore. The black dots existing in the microstructures are the precipitates and were also seen in the un-etched samples because of a T5 heat treatment was carried out to the AZ91 alloy. A detailed SEM micrograph and EDS analysis of the matrix were given in Fig 4. It is observed that there is a dynamic re-crystallization zone which has a much more fine grain size than the base alloy at the interfaces (Fig 5). A plastically deformed zone is also observed just near the interfaces. Although $\mathrm{Mg}$ alloys have a limited plastic deformation at the ambient temperatures, they can be deformed plastically at the elevated temperatures[1].

The width of the dynamic re-crystallization zone differed with variation on the welding conditions. Table 2 shows this dependence. The ultimate temperature at the interface increased with increasing the friction speed, pressure and duration. The microstructure of the welding interface (width of the dynamic re-crystallization zone) was defined by mechanical properties of the material at the ultimate temperature achieved. The width of the dynamic re-crystallization zone increased with increasing friction duration at the lower friction speed for a constant pressure as seen in Table 2. On the other hand, at the higher friction speed, the widths of the dynamic re-crystallization zone increased with increasing friction duration up to $10 \mathrm{~s}$. for both lower and higher friction pressure. The friction durations more than $10 \mathrm{~s}$. caused to reduce in the width of the dynamic re-crystallization zone due to more flash formation at the friction speed of $1000 \mathrm{rpm}$. Due to the temperature of the welding interface was too high and the plastic deformation resistance of the interface was too low at these welding conditions. The friction pressure applied to the samples led to an increase in the interface temperature together with the amount of flash which occurred with plastic deformation. The reason of tighter dynamic re-crystallization zone for $75 \mathrm{MPa}$ pressure than $50 \mathrm{MPa}$ pressure at the friction speed of $1000 \mathrm{rpm}$ is due to more flash formation.

The detailed microstructures of the dynamic re-crystallization zone and AZ91 matrix are shown in Fig 5. It is obvious from the figures that the dynamic re-crystallization zone exhibit grain size lower than 10 $\mu \mathrm{m}$ and approximately equi-axial grain shape. 

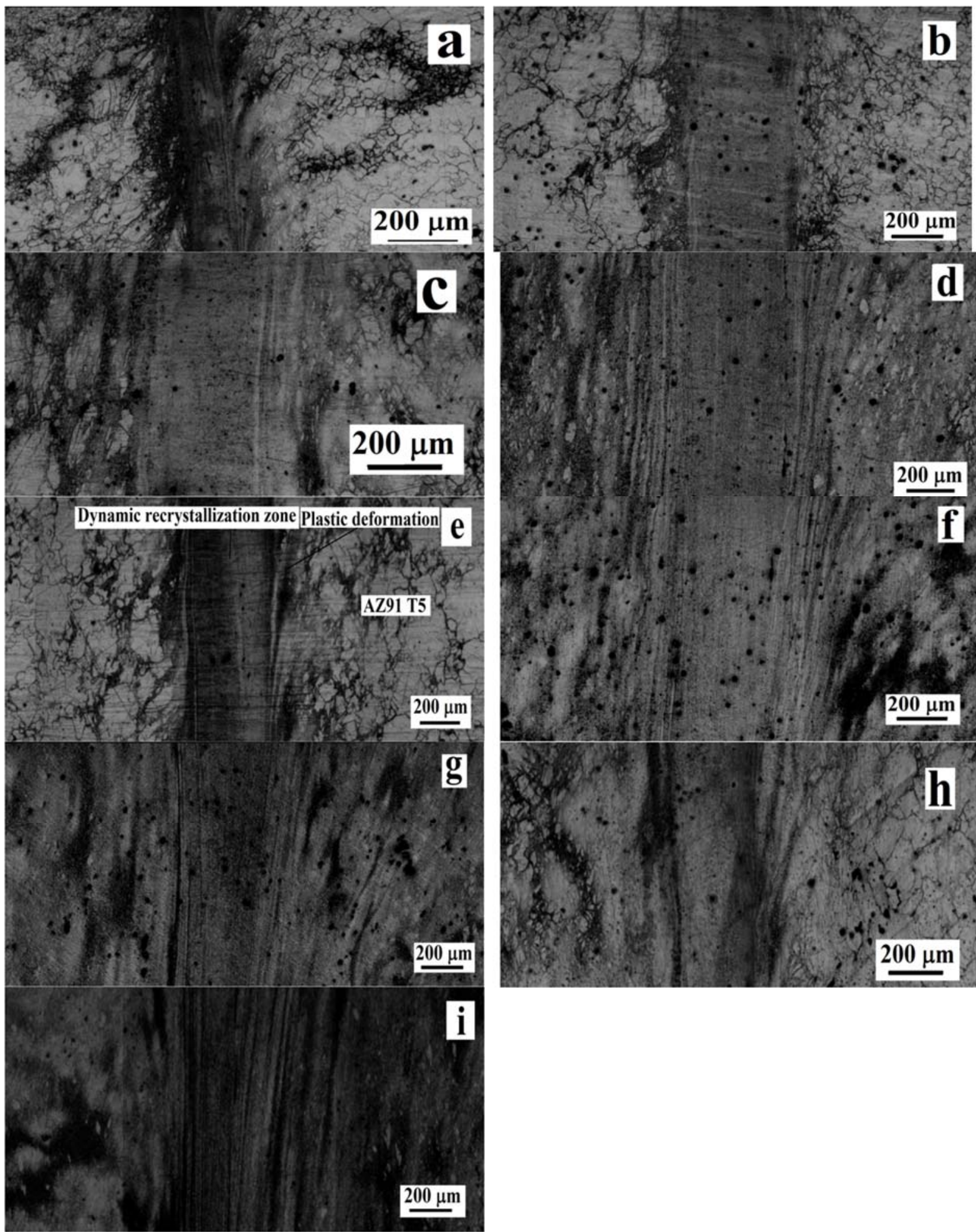

i

Figure 3. The micrographs of the welding interfaces. a) $600 \mathrm{rpm}, 50 \mathrm{MPa}, 10 \mathrm{~s}$, b) $600 \mathrm{rpm}, 50 \mathrm{MPa}, 15 \mathrm{~s}$, c) $600 \mathrm{rpm}, 75 \mathrm{MPa}, 10 \mathrm{~s}$, d) $600 \mathrm{rpm}, 75 \mathrm{MPa}, 15 \mathrm{~s}$, e) $1000 \mathrm{rpm}, 50 \mathrm{MPa}, 5 \mathrm{~s}$, f) $1000 \mathrm{rpm}, 50 \mathrm{MPa}$, $10 \mathrm{~s}, \mathrm{~g}) 1000 \mathrm{rpm} 50 \mathrm{MPa}, 15 \mathrm{~s}$, h) $1000 \mathrm{rpm} 75 \mathrm{MPa}, 5 \mathrm{~s}$, i) $1000 \mathrm{rpm} 75 \mathrm{MPa}, 10 \mathrm{~s}$ 
Çelikyürek and Önal / Anadolu Univ. J. of Sci. and Technology A - Appl. Sci. and Eng. 17 (3) - 2016

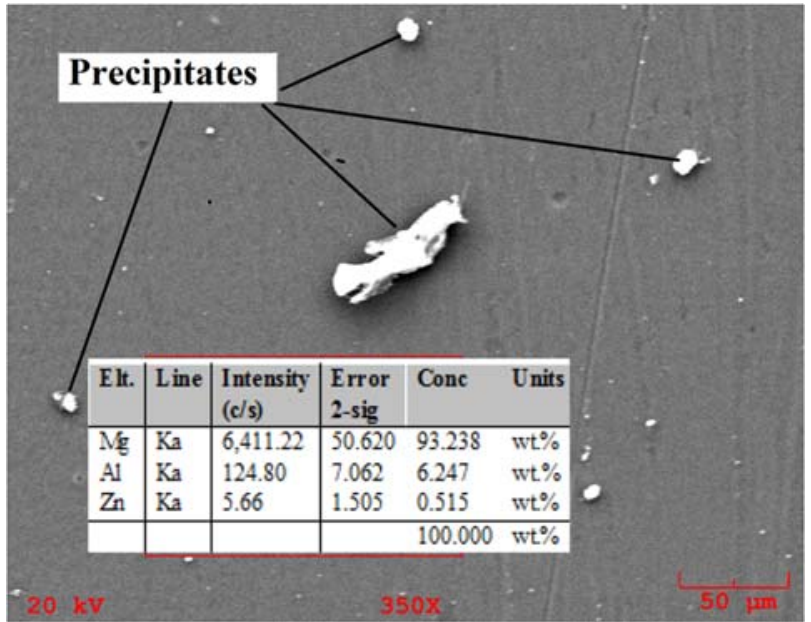

Figure 4. The SEM image and EDS analysis of the AZ91 alloy
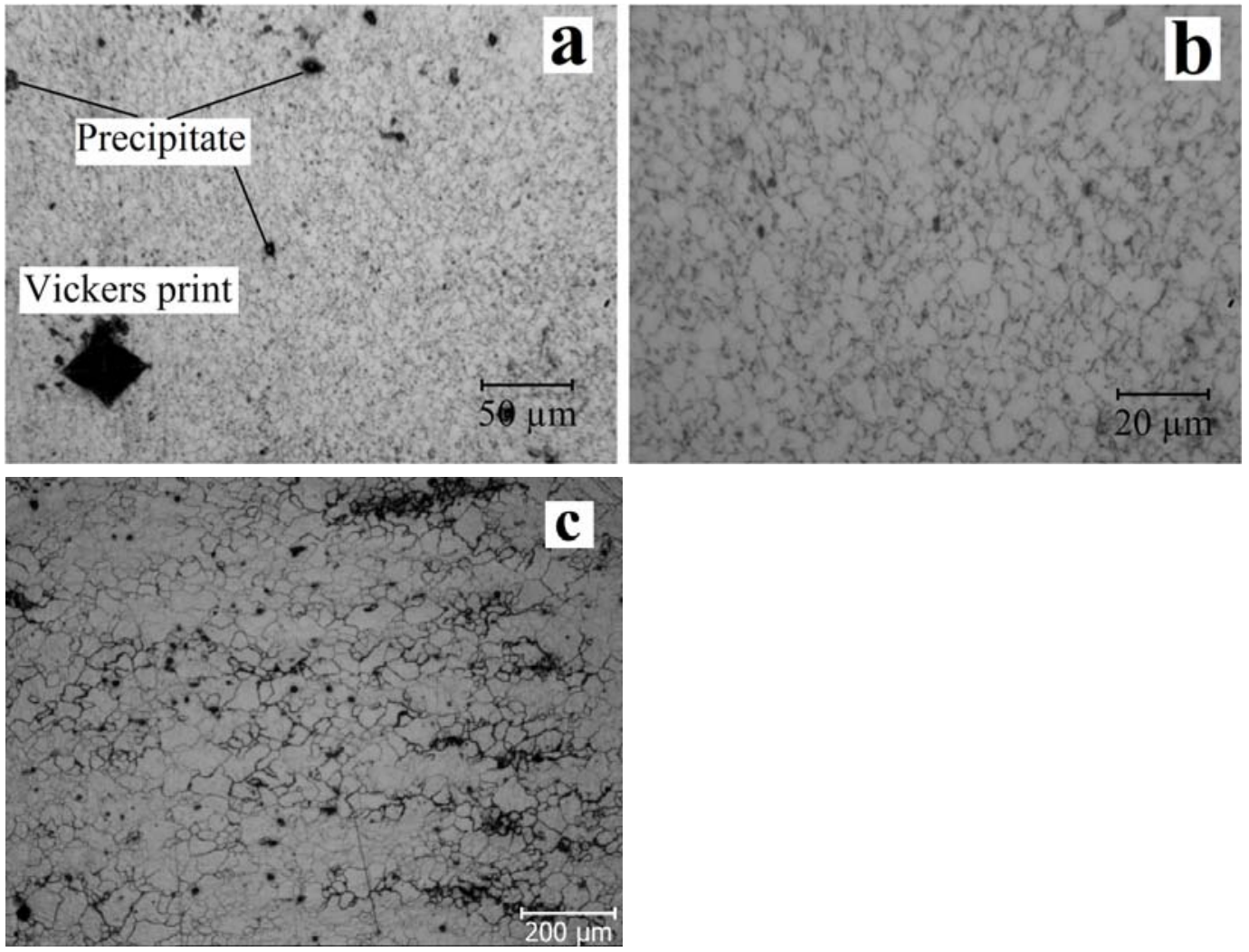

Figure 5. The microstructure of dynamic re-crystallization zone of sample welded at $1000 \mathrm{rpm}$, under $50 \mathrm{MPa}$, and duration of $10 \mathrm{~s}$. in both lower (a) and higher (b) magnifications. (c) The microstructure of the AZ91 matrix 
Table 2. The widths of the dynamic re-crystallization zones, $\mu \mathrm{m}$

\begin{tabular}{|c|c|c|c|c|c|c|}
\hline \multirow{2}{*}{$\begin{array}{c}\text { Friction } \\
\text { pressure } \\
(\mathrm{MPa})\end{array}$} & \multicolumn{6}{|c|}{ Friction speed (rpm) } \\
\cline { 2 - 7 } & \multicolumn{6}{|c|}{ Friction time (s) } \\
\cline { 2 - 7 } & 5 & 10 & 15 & 5 & 10 & 15 \\
\hline 50 & $\mathrm{X}$ & 201 & 461 & 440 & 505 & 425 \\
\hline 75 & $\mathrm{X}$ & 295 & 627 & 271 & 393 & $\mathrm{X}$ \\
\hline
\end{tabular}

The microhardness deviation from the center of the interlayer to the AZ91 matrix was given in Fig. 6 . Three measurements were made for each point. The hardness deviation trends of the all welding conditions are similar. The hardness' of the welding interfaces are higher than the matrix obtained for all welding conditions while the hardness of AZ91 T5 alloy is about $80 \mathrm{HV}$. This situation is due to finer grain size existing in the dynamic re-crystallization zone. A slight reduction in hardness was observed from the center to the matrix. The reason of this deviation is that a plastically deformed zone exists at the boundary of the dynamic re-crystallization zone sides. The figures show the effect of grain size and plastic deformation on the hardness of AZ91 alloy.

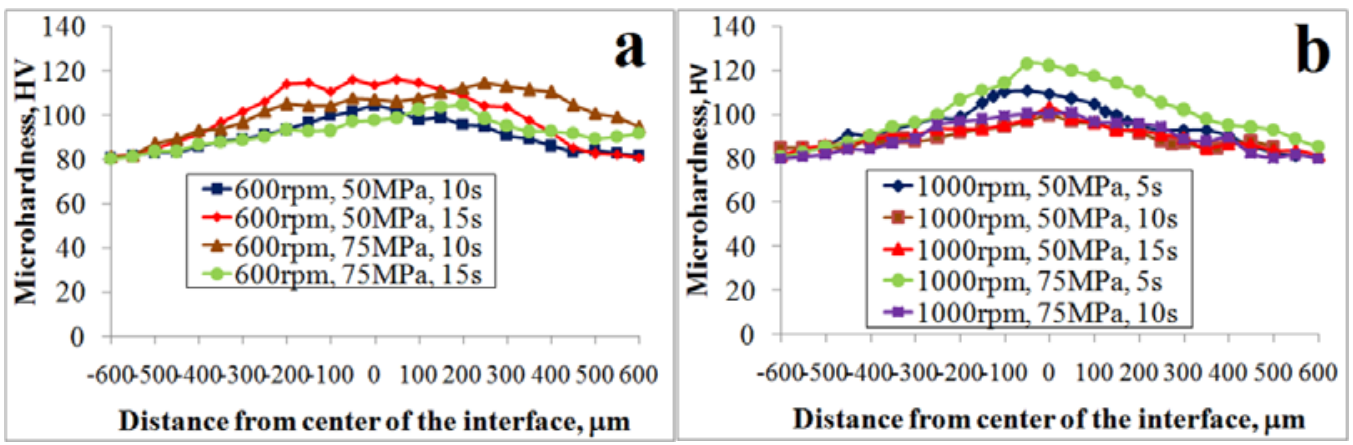

Figure 6. The microhardness deviations of the welding interfaces. (a) $600 \mathrm{rpm}$, (b) $1000 \mathrm{rpm}$ friction speeds

The shear strengths of the welding interfaces were shown in Fig. 7. The AZ91 T5 alloy has shear strength of $140 \mathrm{MPa}$. It is obvious from the figure that generally, the strength of the welding interface increased with increasing the friction pressure and time. However, the shear strength decreases under the high friction pressure at 600rpm friction (Fig. 7a). In addition, the bonding is unsuccessful for $15 \mathrm{~s}$ and at the $1000 \mathrm{rpm}$ friction speed due to too much flash formation (Fig. 7b). If the welding parameters are correctly selected the strength can be obtained as base alloy. Both increase in the friction pressure and the time is resulted with an increase in temperature at the interface. The bonding between two materials can be stronger at higher temperature.

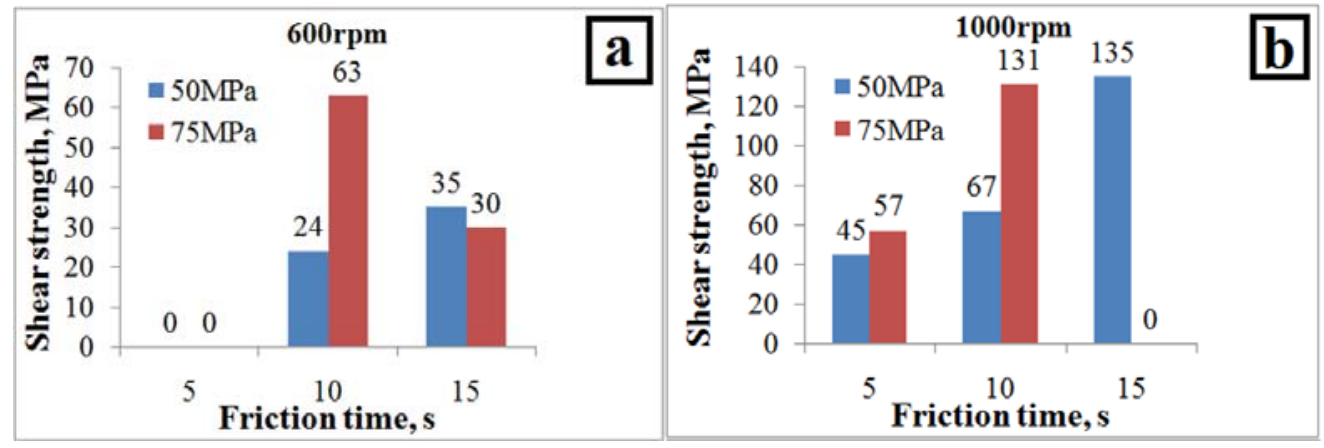

Figure 7. The shear strengths of the welding interfaces 
After shear tests, the fractured surfaces of the base alloy and welded samples are given in Fig. 8. It is understood from the figures that all the welded samples and the base alloy have transgranular brittle fracture. In addition, the grain sizes of the welding interfaces are smaller than AZ91 matrix. The shear test allows ability to deform samples at an exact point and all welded samples have a dynamic recrystallization zone in length of more than $200 \mu \mathrm{m}$. Thus, deformation occurred at the dynamic recrystallization zones for all the welding conditions. These findings are also confirmed by microhardness measurements.
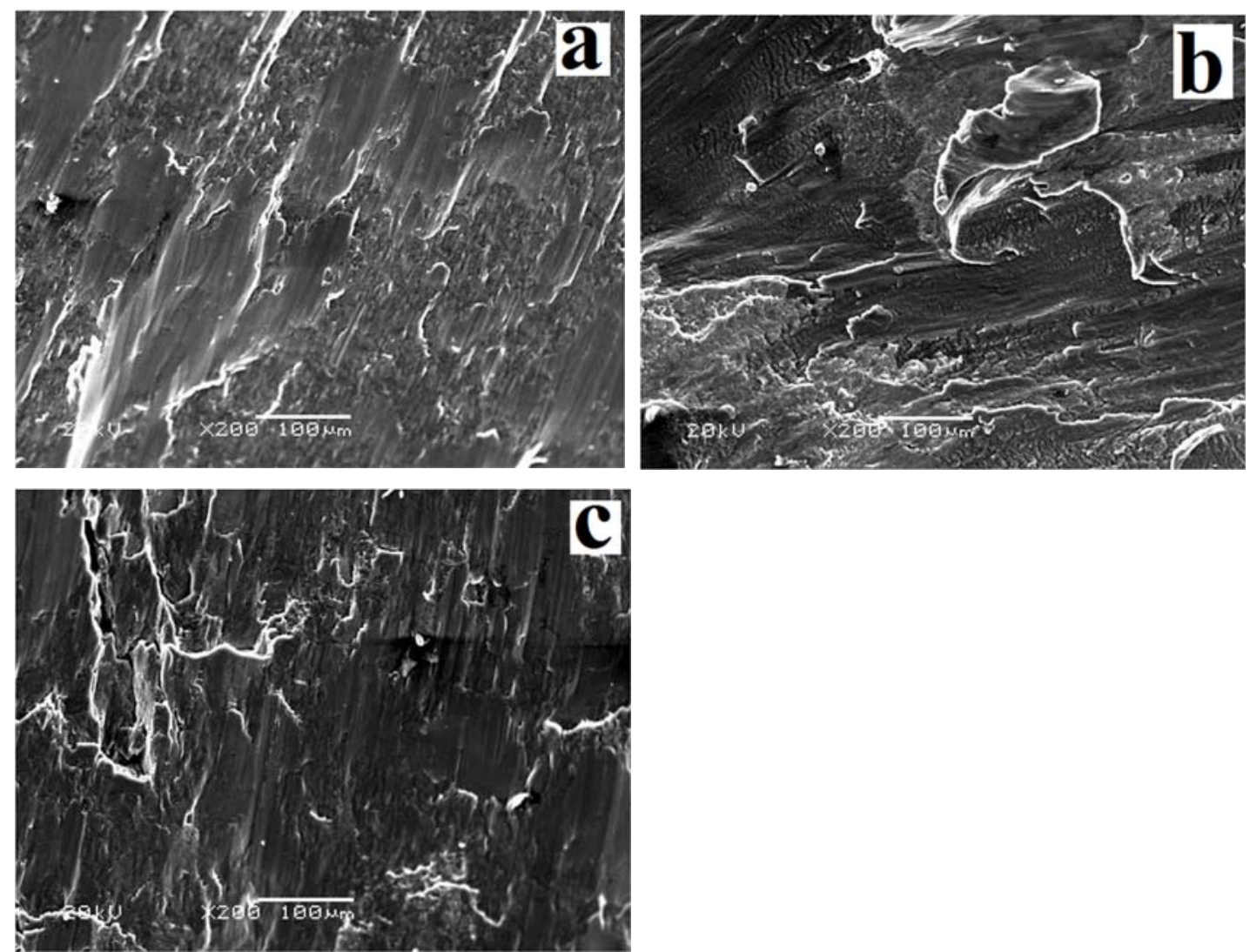

Figure 8. The fractured surface microstructures; a) 1000rpm, 50MPa, 15s, b) $1000 \mathrm{rpm}, 75 \mathrm{MPa}, 5 \mathrm{~s}$, and c) AZ91 T5

\section{CONCLUSION}

When the proper parameters are selected, AZ91 Mg alloy can be bonded by the friction welding process. The friction speed, pressure and time are the most important parameters for friction welding process which affect the strength of the welding interface. In the solid-state welding techniques, the temperature of the interface defines the quality of the welding. Since the heat input is generated at the interface that increases with increasing of the process speed, pressure and time thus the strength of the interface increases in the friction welding. However, achieving the plastic deformation resistance of the materials at the ultimate temperature should not be lower than the applied pressure for a successful bonding. When the applied pressure is higher than the plastic deformation resistance, the materials are altered to be flash trough plastic deformation. The strength of the welding can be very close to the $\mathrm{Mg}$ alloy if the parameters are optimized and properly selected. For these friction welding conditions, friction speed of $1000 \mathrm{rpm}$, friction pressure of $50 \mathrm{MPa}$ and friction duration of $15 \mathrm{~s}$. or $1000 \mathrm{rpm}$ friction speed, $75 \mathrm{MPa}$ friction pressure and $10 \mathrm{~s}$. friction duration are the most proper welding conditions. Because, the measured strengths of the welds are found the highest and very close to the base alloy for these conditions. 
Çelikyürek and Önal / Anadolu Univ. J. of Sci. and Technology A - Appl. Sci. and Eng. 17 (3) - 2016

\section{REFERENCES}

[1] Chai F, Zhang D, Zhang W, Li Y. Microstructure evolution during high strain rate tensile deformation of a fine-grained AZ91 magnesium alloy,Mater. Sci. and Eng. A., 2014; 590:80-87.

[2] Sunil B, Reddy G, Mounika ASN, Sree P, Pinneswari P, Ambica I, Babu R, Amarnadh P. Joining of AZ31 and AZ91 Mg alloys by friction stir welding, J. of Mag. and Alloy., 2015; 3:330-334.

[3] Bannour S, Abderrazak K, Mhiri H, Palec G. Effects of temperature-dependent material properties and shielding gas on molten pool formation during continuous laser welding of AZ91 magnesium alloy, Opt. and Laser Tech., 2012; 44:2459-2468.

[4] Kouadri A, Barrallier L. Texture characterization of hexagonal metals: Magnesium AZ91 alloy, Mater. Sci. and Eng. A., 2006; 429:11-17.

[5] Yuan T, Chai X, Luo Z, Kou S. Predicting susceptibility of magnesium alloy to weld-edge cracking, Act. Materi., 2015; 90:242-251.

[6] Zhu T, Chen Z, Gao W. Microstructure formation in partially melted zone during gas tungsten arc welding of AZ91 Mg cast alloy, Mater. Charac., 2008; 59:1550-1558.

[7] Wen T, Liu S, Chen S, Liu L, Yang C. Influence of high frequency vibration on microstructure and mechanical properties of TIG welding joints of AZ31 magnesium alloy, Trans. Nonfer. Mater. Soc. China, 2015; 25:397-404.

[8] Braszczynska-Malik K, Mroz M. Gas-tungsten arc welding of AZ91 magnesium alloy, J. of Alloy. and Comp., 2011; 509:9951-9958.

[9] Torun O, Karabulut A, Baksan B, Çelikyürek İ. Diffusion bonding of AZ91 using a silver interlayer, Mater. and Desi., 2008; 29:2043-2046.

[10] Niknejad S, Liu L, Lee M, Esmaeili S, Zhou N. Resistance spot welding of AZ series magnesium alloys: Effects of aluminum content on microstructure and mechanical properties, Mater. Sci. and Eng. A., 2014; 618:323-334.

[11] Xiao L, Liu L, Chen DI, Esmaeili S, Zhou Y. Resistance spot weld fatigue behavior and dislocation substructures in two different heats of AZ31 magnesium alloy, Mater. Sci. and Eng. A., 2011; 529:8187.

[12] Hosseini VA, Aashuri H, Kokabi AH. Characterization of newly developed semisolid stir welding method for AZ91 magnesium alloy by using Mg-25\%Zn interlayer Mater. Sci. and Eng. A., 2013; 565:165-171.

[13] Yin YH, Sun N, North TH, Hu SS. Microstructures and mechanical properties in dissimilar AZ91/AZ31 spot welds Mater Charac., 2010; 61:1018-1028.

[14] Rao HM, Yuan W, Badarinarayan H. Effects of process parameters on mechanical properties of friction stir spot welded magnesium to aluminum alloys, Mater and Desi., 2015; 66:235-245.

[15] Çelikyürek İ, Torun O, Baksan B. Microstructure and strength of friction-welded Fe-28Al and 316 1 stainless steel Mater. Sci. and Eng. A., 2011; 528:8530-8536. 
Çelikyürek and Önal / Anadolu Univ. J. of Sci. and Technology A - Appl. Sci. and Eng. 17 (3) - 2016

[16] Özdemir N. Investigation of the mechanical properties of friction-welded joints between AISI 304L and AISI 4340 steel as a function rotational speed Mater. Lett., 2005; 59:2504-2509.

[17] Ateş H, Turker M, Kurt A. Effect of friction pressure on the properties of friction welded MA956 iron-based superalloy Mater. and Desi., 2007; 28:948-953.

[18] Torun O, Çelikyürek İ, Baksan B. Friction welding of cast Fe-28Al alloy Intermetal., 2011; 19:1076-1079. 